University of Nebraska - Lincoln

DigitalCommons@University of Nebraska - Lincoln

$10-2003$

\title{
Morph-dependent fatty acid oxidation in a wing-polymorphic cricket: Implications for the trade-off between dispersal and reproduction
}

\author{
Anthony J. Zera \\ University of Nebraska - Lincoln, azera1@unl.edu \\ Zhangwu Zhao \\ University of Nebraska - Lincoln
}

Follow this and additional works at: https://digitalcommons.unl.edu/bioscizera

Part of the Microbiology Commons

Zera, Anthony J. and Zhao, Zhangwu, "Morph-dependent fatty acid oxidation in a wing-polymorphic cricket: Implications for the trade-off between dispersal and reproduction" (2003). Anthony Zera Publications. 32.

https://digitalcommons.unl.edu/bioscizera/32

This Article is brought to you for free and open access by the Papers in the Biological Sciences at DigitalCommons@University of Nebraska - Lincoln. It has been accepted for inclusion in Anthony Zera Publications by an authorized administrator of DigitalCommons@University of Nebraska - Lincoln. 
Published in Journal of Insect Physiology 49:10 (October 2003), pp. 933-943;

doi 10.1016/S0022-1910(03)00152-5 Copyright ( 2003 Elsevier Ltd.

Used by permission. http://www.sciencedirect.com/science/journal/00221910

Submitted January 3, 2003; accepted June 4, 2003; published online August 28, 2003.

\title{
Morph-dependent fatty acid oxidation in a wing-polymorphic cricket: Implications for the trade-off between dispersal and reproduction
}

\author{
Anthony J. Zera and Zhangwu Zhao \\ School of Biological Sciences, University of Nebraska-Lincoln, Lincoln, NE 68588, USA \\ Corresponding author-A. J. Zera, tel 402 472-2768, fax 402 472-2083, email azera1@unl.edu
}

\begin{abstract}
Although a considerable amount of information is available on the ecology and physiology of wing polymorphism, much less is known about the biochemical-genetic basis of morph specialization for dispersal versus reproduction. Previous studies have shown that the dispersing morph of the wing-polymorphic cricket, Gryllus firmus, prioritizes the accumulation of triglyceride flight fuel over ovarian growth, while the opposite occurs in the flightless morph during the first week of adulthood. In this study, we compared the in vivo rate of lipid oxidation between genetic stocks of flight-capable versus flightless morphs to determine the role of lipid catabolism in morph specialization for flight versus reproduction. During the first five days of adulthood, in the absence of flight, fatty acid oxidation was substantially lower in the dispersing morph relative to the flightless morph, when either radiolabeled acetate or palmitate was used as a substrate. Differences between the morphs in fatty acid oxidation were genetically based, occurred co-incident with morph-specific differences in triglyceride accumulation and ovarian growth, and were observed on a variety of diets. A genetically based trade-off in the relative conversion of palmitate into $\mathrm{CO}_{2}$ versus triglyceride was observed in morphs of G. firmus. Decreased oxidation of fatty acid and increased biosynthesis of triglyceride, both appear to play an important role in flight fuel accumulation, and hence morph specialization for flight. Conversely, increased oxidation of fatty acid likely fuels the enhanced ovarian growth in the flightless morph. The results of the present study on fatty acid catabolism, and previous studies on triglyceride and phospholipid biosynthesis, provide the first direct evidence that genetically based differences in in vivo flux through pathways of intermediary metabolism underlie a trade-off between flight capability and reproduction-a trade-off of central importance in insects.
\end{abstract}

Keywords: wing polymorphism, lipid, lipid oxidation, trade-off, life history, dispersal

\section{Introduction}

Dispersal polymorphism occurs widely in the Insecta and involves discontinuous variation in a wide variety of traits involved in flight and reproduction (Dingle, 1996; Zera and Denno, 1997; Zera and Harshman, 2001). One morph contains fully developed wings and flight muscles and is capable of flight. By contrast, one or more morphs have reduced wings and flight muscles, or reduced flight muscles alone, and cannot fly. Importantly, flight capability is negatively associated with egg production. That is, ovarian growth is substantially faster and egg production is substantially greater in the flightless compared with the flight-capable morph during early adulthood.

Dispersal polymorphism has been used extensively as a model to investigate a wide variety of issues related to the evolution, ecology, and physiology of dispersal, reproduction, and the negative interaction (tradeoff) between these two important organismal functions (Dingle, 1996; Zera and Denno, 1997; Zera and Harshman, 2001). A number of physiological studies have 
documented differences between morphs in energetic or endocrine aspects of flight capability and egg production (reviewed in Zera and Denno, 1997; Zera et al., 1998; Zera and Harshman, 2001). However, much less is known about the biochemical underpinnings of these physiological differences (Zera et al., 1999; Zera and Harshman, 2001; Zhao and Zera, 2001, 2002; Zera and Zhao, 2003).

We have been using the wing-polymorphic cricket, Gryllus firmus, as a model to investigate physiological, biochemical, and molecular bases of adaptations of morphs for dispersal versus reproduction. An important focus of our studies is variation in lipid metabolism between morphs (Zera et al., 1994, 1998, 1999; Zera and Brink, 2000; Zera and Harshman, 2001). Lipid is the major flight fuel in species of Gryllus (Zera et al., 1999), as is the case for many other insects, especially orthopterans (Beenakkers et al., 1985; Candy, 1989). Like other dispersal-polymorphic insects (Uvarov, 1966; Newanze et al., 1976; Gunn and Gatehouse, 1987), the dispersing morph of G. firmus has significantly greater whole-body triglyceride than the reproductive morph during adulthood (Zera et al., 1994; Zera and Larsen, 2001; see Discussion). Furthermore, triglycerides accumulate to a greater degree in flight-capable females during the same period in adulthood when ovaries grow to a lesser degree in that morph relative to flightless females. Thus, the flightcapable G. firmus appears to be programmed to accumulate triglyceride flight fuel at the expense of ovarian growth during early adulthood, while the flightless morph prioritizes ovarian growth over triglyceride accumulation (see Discussion).

Recent in vitro and in vivo studies point to increased lipid biosynthesis as an important cause of increased lipid accumulation in the flight-capable morph of G. firmus (Zhao and Zera, 2001, 2002; Zera and Zhao, 2003). However, the concentration of lipid reserves in each morph results from the combined effects of oxidation as well as biosynthesis. There currently are no published data on morph-specific rates of lipid oxidation for any case of dispersal polymorphism. To attain a deeper understanding of the mechanisms that control the differential production of lipid reserves between morphs, we compared the in vivo oxidation of lipid in flight-capable and flightless morphs of G. firmus in the absence of flight. Because we are primarily interested in the evolution of morph specialization, measurements were undertaken in replicated pairs of genetic stocks that produce primarily the flight-capable or flightless morphs. Finally, we measured the relative oxidation versus incorporation of fatty acid into lipid components to directly determine whether there was a genetically based trade-off between these aspects of lipid metabolism in morphs of G. firmus.

\section{Materials and methods}

\subsection{Backgound on G. firmus: morphs, selected stocks, and rearing conditions}

Gryllus firmus, the sand cricket, occurs in the southeastern USA as a long-winged (LW) morph, some of which are capable of flight, or as a short-winged (SW) morph that is obligatory flightless (Veazy et al., 1976). Except in a few rare cases, SW females molt into adults with white, non-functional, underdeveloped flight muscles. All LW females have large, pink flight muscles at the adult molt and are denoted "LW(f)." Some LW(f) individuals histolyze (degenerate) their flight muscles, starting on about day 5 thus becoming flightless - denoted LW(h); see Zera et al. (1997). In the selected lines used in the present study only a few $(<5 \%) \mathrm{LW}(\mathrm{h})$ individuals were produced. Biochemical characterizations of these $\mathrm{LW}(\mathrm{h})$ females will be reported elsewhere.

G. firmus females were taken from lines artificially selected for wing morph (18th generation of selection). The experimental design consisted of three blocks (independent selection trials), each of which contained a line selected for the LW morph (" $\mathrm{L}$ " line; producing > 90\% LW females), and a line selected for the SW morph ("S" line; producing > 90\% SW females) - see Figure 1 of Zera and Bottsford (2001), or Zera and Cisper (2001). Blocks also contained unselected control lines which were not studied. Crickets were reared at $28{ }^{\circ} \mathrm{C}$ under a 16L:8D photoperiod, at a density of 80 and 40 crickets per 10 gallon aquarium during the penultimate and last stadium, respectively. Crickets were switched from the standard "dry" diet to the standard 100\% wet diet same components as the dry diet but made up in $2.5 \%$ aqueous agar; see Zera and Larsen (2001) and Zhao and Zera (2001) - during the penultimate stadium. Crickets used for experiments were checked for molting at $24 \mathrm{~h}$ intervals and equal numbers of newly molted females and males were raised together at a density of 4-6 per 1 gallon plastic box or 8-12 per 3 gallon plastic box.

Rates of lipid oxidation were quantified in female morphs on day 0 (day of molt) and day 5 of adulthood. Day 5 was chosen because this is the period of time during which there is a dramatic trade-off between ovarian growth and accumulation of triglyceride reserves (see Zera and Larsen, 2001, and Discussion). Day zero was chosen as a baseline, to determine in vivo rates of lipid oxidation prior to the occurrence of the trade-off mentioned above.

Comparisons were made between morphs fed one of three diets starting on the first day of adulthood. This was done to determine the extent to which morph-specific differences in lipid oxidation were independent of diet. The three diets differed dramatically in total usable calories and in the content of various macronutri- 
ents such as protein, carbohydrate and lipid. Diets were the same as those used in our prior studies of lipid reserves and biosynthesis in morphs of G. firmus (Zera and Larsen, 2001; Zhao and Zera, 2002; Zera and Zhao, 2003). All juveniles were raised on the standard ("high") diet. Starting on the day of adult molt, one group of adults was fed this same diet. A second group of adults was fed a low nutrient ("low") diet in which $75 \%$ of the dry mass of the high-nutrient diet had been replaced with nonnutritive cellulose. Growth in two Gryllus species, G. assimilis and G. firmus, is substantially reduced on this diet (Zera et al., 1998; Zera and Brink, 2000). A third group of crickets was fed a high-carbohydrate diet ("sucrose"), in which $67 \%$ of the cellulose of the low nutrient diet was replaced with sucrose (ca $9 \%$ sucrose w/w). A high carbohydrate diet was used since lipid metabolism is often strongly affected by the quantity of carbohydrate in the diet (Geer and Laurie-Ahlberg, 1984; Downer, 1985). All diets had the same dry mass and water content.

\subsection{Quantification of rates of lipid oxidation using [1- ${ }^{14}$ C] acetate and $\left[1-{ }^{14} \mathrm{C}\right]$ palmitate}

In vivo rates of lipid oxidation were quantified in flightcapable [LW(f)] and flightless (SW) morphs by standard techniques (Downer, 1985) in which the amount of ${ }^{14} \mathrm{C}$ from $\left[1-{ }^{14} \mathrm{C}\right]$ palmitic acid or $\left[1-{ }^{14} \mathrm{C}\right] \mathrm{Na}$-acetate incorporated into $\mathrm{CO}_{2}$ was measured during a standard period of time. This technique essentially quantifies whole-organism oxidation of lipid, which primarily consists of oxidation of lipid reserves in a variety of organs (Downer, 1985). Two $\mu$ l of phosphate-buffered saline $(\mathrm{pH} 7.0)$ containing $1 \times 10^{6} \mathrm{DPM}\left[1-{ }^{14} \mathrm{C}\right]$ palmitic acid (2.1 GBq/mmol; 56 mCi/mmol; New England Nuclear) were injected into the hemocoel of individual crickets that had been fasted for $4 \mathrm{~h}$ prior to injection. After injection, crickets were placed singly in $50 \mathrm{ml}$ glass Erlenmeyer flasks containing a small piece of artificial diet. Flasks were tightly sealed with a rubber stopper and parafilm. Near the top of the stopper within the flask was a small cup containing $300 \mu \mathrm{l}$ of $20 \% \mathrm{NaOH}$ from which protruded two pieces of filter paper to trap $\mathrm{CO}_{2}$ respired by the crickets. Crickets were incubated for 4 $\mathrm{h}$ at $28^{\circ} \mathrm{C}$. After this time, for each flask, filter papers, $\mathrm{NaOH}$ solution, and three aqueous rinses of the cup that contained the $\mathrm{NaOH}$ solution, were placed in a scintillation vial, scintillation cocktail was added, and DPM determined. Background studies demonstrated that incorporation of radiolabel into $\mathrm{CO}_{2}$ was linear during the $4 \mathrm{~h}$ incubation period (Figure 1).

In addition to measuring the in vivo rate of oxidation of palmitic acid to $\mathrm{CO}_{2}$ we also measured incorporation of this fatty acid into triglyceride and phospholipid. This was done so that we could compare the extent to which fatty acid is oxidized to produce energy versus used to biosynthesize triglyceride flight fuel or phospholipid in flight-capable and flightless morphs. Details of the methods and results of the biosynthetic studies can be found in Zhao and Zera (2002). Here we only present percentage radiolabel from palmitic acid that was incorporated into $\mathrm{CO}_{2}$, triglyceride, and phospholipid, and correlations between these percentages.

As an independent measure of lipid oxidation we quantified the incorporation of ${ }^{14} \mathrm{C}$ from ${ }^{14} \mathrm{C}$-acetate, the end product of B-oxidation of lipid, into $\mathrm{CO}_{2}$. Two microliters of sterile saline $(0.9 \% \mathrm{NaCl})$ containing ca $6 \times 10^{5}$ DPM of $\left[1-{ }^{14} \mathrm{C}\right] \mathrm{Na}$-acetate $(2.0 \mathrm{GBq} / \mathrm{mmol} ; 54.7 \mathrm{mCi} /$ mmol; New England Nuclear) were injected into the abdominal hemocoel of adult female crickets that had been fasted for $4 \mathrm{~h}$ prior to injection. Crickets were incubated as described above, but for $7 \mathrm{~h}$, since incorporation of ${ }^{14} \mathrm{C}$ from acetate into $\mathrm{CO}_{2}$ was linear during this period of time (see Figure 1).

\subsection{Statistical analyses}

To determine if rates of palmitate or acetate oxidation differ genetically between LW(f)-selected versus SWselected G. firmus, mean palmitate or acetate oxidation
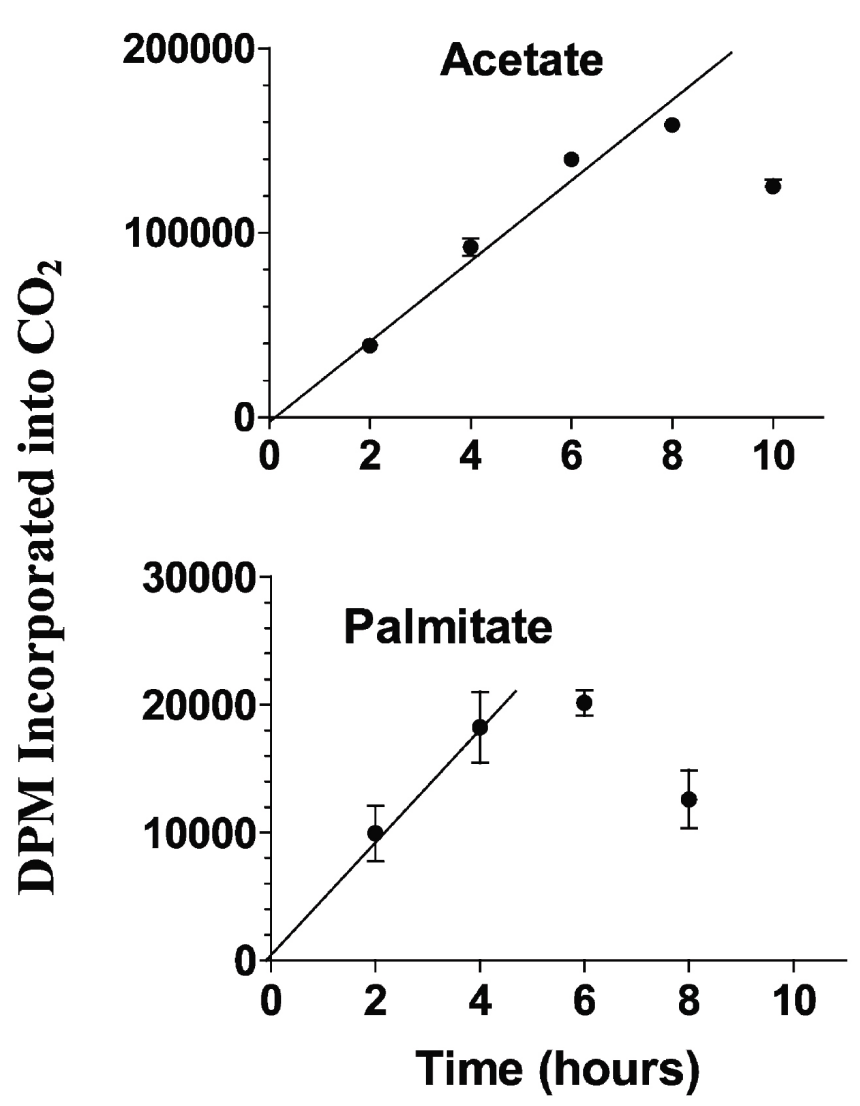

Figure 1. Time course of ${ }^{14} \mathrm{CO}_{2}$ production from $\left[1-{ }^{14} \mathrm{C}\right]$ acetate or $[1-14 \mathrm{C}]$ palmitate injected into adult G. firmus females. Values are means of three replicates $( \pm$ SEM). Regression lines were drawn through linear portions of the progress curves. $r^{2}$ values for acetate and palmitate incorporation were 0.97 and 0.87 , respectively. 
was compared between the three pairs of $\mathrm{LW}(\mathrm{f})$ and SW stocks using a paired $t$-test, essentially as performed in Zera and Larsen (2001), Zera and Cisper (2001), and Zhao and Zera (2002); also see Rose et al. (1996). This test determines whether there is a consistent (=genetic) difference between the mean rate of oxidation of palmitate or acetate in a LW(f) stock compared to the SW stock of the same block, averaged across the three blocks. Genetic differences between $\mathrm{LW}(\mathrm{f})$ and $\mathrm{SW}$ females in lipid oxidation were also assessed by determining:

1. whether individual LW(f) females from an L line differed from SW females from the $S$ line of the same block (using a standard unpaired $t$-test); and

2. whether these differences were consistent (i.e., of the same rank order) across the three blocks.

In an analogous manner, the existence of genotype (morph)×environment (diet) interactions for rates of lipid oxidation was ascertained by determining whether there was a significant within-block morph $\times$ diet interaction that was consistent across the three blocks.

The existence of a genetically based trade-off between fatty acid oxidation versus conversion into triglyceride and phospholipid in G. firmus was tested as follows. First, we calculated the percentage DPM incorporated into $\mathrm{CO}_{2}$ plus total lipid ( $>90 \%$ triglyceride and phospholipid; see Zera and Larsen, 2001) that was due to $\mathrm{CO}_{2}$ [DPM $\left(\mathrm{CO}_{2}\right) /\left(\mathrm{DPM}\left(\mathrm{CO}_{2}+\right.\right.$ total lipid)] for each of the three LW(f) stocks and three SW stocks. Mean percentage incorporation into $\mathrm{CO}_{2}$ was then compared between the three pairs of $\mathrm{LW}(\mathrm{f})$ and SW stocks using a paired $t$-test (in a manner analogous to comparisons of palmitate or acetate oxidation in pairs of $L W(f)$ and SW stocks described above). In addition, we determined whether $L W(f)$ and SW females differed in the proportional incorporation of radiolabel into $\mathrm{CO}_{2}$ versus total lipid within each block. This was done using ANCOVA in which the dependent variable (numerator) was DPM incorporated into $\mathrm{CO}_{2}$ and the covariate (denominator) was DPM incorporated into $\mathrm{CO}_{2}$ plus total lipid. Preliminary ANCOVAs indicated no significant morph $\times$ diet interaction for any block (i.e. differences between morphs were statistically equivalent on the three diets). Thus, results of ANCOVAs and ratios of relative incorporation of radiolabel into $\mathrm{CO}_{2}$ versus total lipid are only given as values pooled across diets. Although relative incorporation of ${ }^{14} \mathrm{C}$ from $\left[{ }^{14} \mathrm{C}\right.$ ]palmitate into $\mathrm{CO}_{2}$ versus total lipid was measured in the same individuals, results of incorporation studies into total lipid have been reported previously (Zhao and Zera, 2002). Here we only give results of the relative incorporation into $\mathrm{CO}_{2}$ versus total lipid for LW(f) and SW stocks.

Spearman (non-parametric) correlations were calculated between the percentage of ${ }^{14} \mathrm{C}$ from [1$\left.{ }^{14} \mathrm{C}\right]$ palmitate that was incorporated into $\mathrm{CO}_{2}$, triglycer- ide, and phospholipid within SW or LW(f) individuals of the same block. Spearman correlations were estimated because percentage incorporation is not normally distributed. Significance tests took into account the fact that they were estimated from two independent variables. Correlations were computed only on distributions pooled across diets because of the small sample sizes within diets $(N=14-16)$.

\section{Results}

\subsection{Rates of oxidation of palmitate and acetate}

On the first day of adulthood, no genetic differences were observed between LW(f) and SW morphs for fatty acid oxidation (see bottom left panels of Figure 2 and Figure 3). Mean palmitate oxidation to $\mathrm{CO}_{2}$ did not differ between the three $\mathrm{LW}(\mathrm{f})$ and the three SW stocks as determined by a paired $t$-test (Figure 2). Furthermore, when we compared individual morphs within a block rather than stock means across blocks, rate of incorporation of $\left[{ }^{14} \mathrm{C}\right]$ palmitate into $\mathrm{CO}_{2}$ was statistically indistinguishable between $\mathrm{LW}(\mathrm{f})$ females from an L line compared with SW females from a S line of the same stock, for two of three blocks (Figure 2). A similar situation was observed when $\left[{ }^{14} \mathrm{C}\right]$ acetate was the radiolabel (Figure 3). No significant difference was observed between $\mathrm{LW}(\mathrm{f})$ versus SW stock means (paired $t$-test: $p>0.1$ ), or

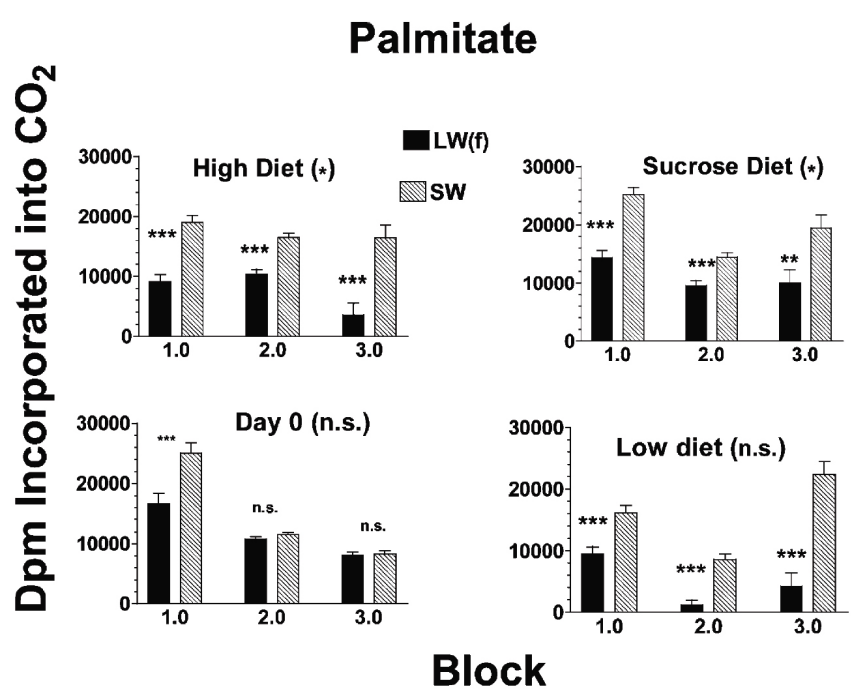

Figure 2. Rate of production of ${ }^{14} \mathrm{CO}_{2}$ from $\left[1-{ }^{14} \mathrm{C}\right]$ palmitate injected into flight-capable [LW(f)] or flightless (SW) G. firmus on day 0 (lower left panel) or day 5 (other panels) of adulthood. Symbols above bars denote results of $t$-tests comparing rates of oxidation between $\mathrm{LW}(\mathrm{f})$ and SW females within blocks [*** $p<0.005,{ }^{* *} p<0.01$, n.s. $=$ non-significant $\left.(p>0.1)\right]$. Symbols within parentheses next to diet treatments or "day 0 " denote results of paired $t$-tests across blocks (n. s. = non-significant; * $p<0.05)$. 


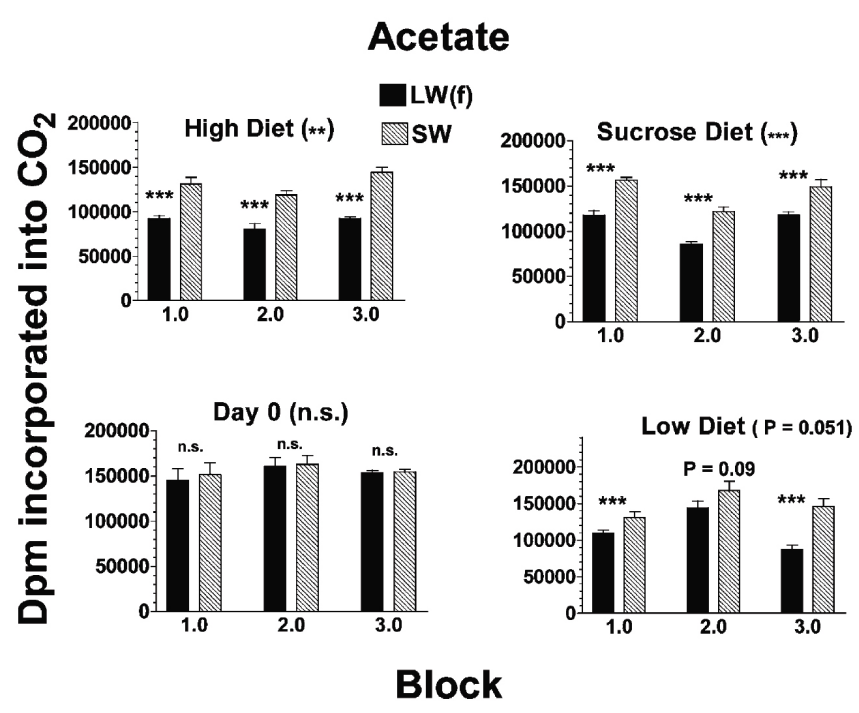

Figure 3. Rate of production of ${ }^{14} \mathrm{CO}_{2}$ from $\left[1-{ }^{14} \mathrm{C}\right]$ acetate injected into flight-capable [LW(f)] or flightless (SW) G. firmus on day 0 (lower left panel) or day 5 (other panels) of adulthood. Symbols above bars denote results of $t$-tests comparing rates of oxidation between LW(f) and SW females within blocks [*** $p<0.005$, n.s. $=$ non-significant $(p>0.1)]$. Symbols within parentheses next to diet treatments or "day 0 " denote results of paired $t$-tests across blocks.

between individual LW(f) or SW females within any of the three blocks $(p>0.1$ for each of three unpaired $t$ tests). Because crickets had been reared exclusively on the "high" diet until the adult molt, all measurements on the first day of adulthood were done only on that diet.

In contrast to day 0 , the SW morph exhibited a consistently higher rate of lipid oxidation to $\mathrm{CO}_{2}$ compared with the LW(f) morph on day 5 of adulthood. Rate of incorporation of $\left[{ }^{14} \mathrm{C}\right]$ palmitate into $\mathrm{CO}_{2}$ was significantly higher in SW females of an S line compared with LW(f) females of an L line within each of the three blocks on each of the three diet treatments (Figure 2). Elevated lipid oxidation in the SW morph was of large magnitude, on average being at least $50 \%$ higher in SW versus LW(f) females within a particular block and diet. Most importantly, mean rate of palmitate oxidation was significantly greater in the SW stocks compared with LW(f) stocks on the "high" and "sucrose" treatments $(p<0.05$ for paired $t$-tests of block means; Figure 2). These data provide strong evidence for a genetically based elevation in lipid oxidation in SW-selected versus LW(f)-selected G. firmus females on these diets. On the "low" diet treatment (Figure 2), mean oxidation did not differ significantly between the three $L W(f)$-selected versus three SW-selected stocks (results of paired $t$-test: $p$ $>0.1$ ). However, this was due to substantial heterogeneity in the degree to which mean lipid oxidation was elevated in a particular pair of SW versus $L W(\mathrm{f})$ stocks (i.e. heterogeneity among blocks). Within each block, lipid oxidation was substantially higher in SW than in
LW(f) females (Figure 2). These results, taken together, also provide evidence for a genetically based elevation in lipid oxidation in SW versus LW(f) females, and suggest that genetic factors responsible for this elevation differ between blocks (e.g. possibly due to blockspecific alleles). No significant MORPH $\times$ DIET interaction was observed within any block (ANOVAs: $p>0.05$ in each block). Thus, lipid oxidation was elevated in SW versus LW(f) females to a similar degree in all diets within a block, providing no evidence for a strong genotype $\times$ morph interaction.

A similar situation was found for oxidation of $\left[{ }^{14} \mathrm{C}\right]$ acetate: the SW morph from an $\mathrm{S}$ line exhibited a significantly higher rate of oxidation than the LW(f) morph from an L line within each block on each of the three diets (Figure 3). The only exception was block-2 crickets fed the "low" diet in which oxidation of acetate was nearly significantly greater $(p=0.09)$ in SW versus LW(f) females. Paired $t$-tests indicated a significant elevation in mean acetate oxidation in SW versus $L W(f)$ stocks fed the "high" and "sucrose" diets, and a nearly significant elevation on the "low" diet $(p=0.051$; Figure 3). As was the case for palmitate oxidation, these results provide strong evidence for a genetically based elevation in acetate oxidation in SW versus $L W(f)$ morphs of G. firmus. No significant MORPH $\times$ DIET interaction was observed for blocks 1 or 3 (ANOVAs; $p>0.1$ ), while a significant interaction was observed for block 2 crickets $\left[F_{(2,27)}=4.37 ; p=0.023\right]$. This interaction was due to a highly significant elevation in lipid oxidation in SW versus LW(f) females on the "high" and "sucrose" diets, coupled with nearly equivalent rates of lipid oxidation on the low diet.

Within most blocks and diet treatments, the higher rate of acetate oxidation in SW versus LW(f) females on day 5 was caused by a lesser drop in lipid oxidation in the SW morph compared with the LW(f) morph over the first 5 days of adulthood (compare the lower left panel of Figure 3 with the other panels in this figure). By contrast, the higher rate of palmitate oxidation in the SW versus $L W(f)$ morph on day 5 did not result from any single pattern of morph-specific change in lipid oxidation during the first five days of adulthood that was consistent across blocks and diet treatments (Figure 2). For example, for block 2 , the elevated rate of lipid oxidation in the SW morph on day 5 on the "high" diet was due to a greater increase in lipid oxidation in that morph relative to the LW(f) morph over the first 5 days of adulthood. By contrast, the higher rate of oxidation in the SW morph in the "low" diet on day 5 was due to a greater decline in the rate of oxidation in the $L W(f)$ versus SW morphs over the first 5 days of adulthood. Finally, there was a strong effect of diet, independent of morph, on rate of lipid oxidation, irrespective of whether acetate or palmitate was the radiolabel (ANOVA; $p<0.005$ in each block for either acetate or palmitate). In four of six cases, 
Table 1. Differential incorporation of $\left[{ }^{14} \mathrm{C}\right]$ palmitate into $\mathrm{CO}_{2}$, triglyceride, and phospholipid in flight-capable [LW(f)] and flightless (SW) G. firmus

\begin{tabular}{|c|c|c|c|c|}
\hline Morph & Block & 2 & 3 & $\begin{array}{l}\text { Paired } t \text {-test of } \\
\text { LW(f) and SW } \\
\text { stocks }\end{array}$ \\
\hline \multicolumn{5}{|c|}{ Percentage conversion into CO2 versus (triglyceride + phospholipid) } \\
\hline $\begin{array}{l}\mathrm{LW}(\mathrm{f}) \\
\text { SW }\end{array}$ & $\begin{array}{l}33.4 \pm 2.8(20)^{* * * a b} \\
46.4 \pm 2.0(20)\end{array}$ & $\begin{array}{l}33.9 \pm 2.9(15)^{* \star *} \\
44.5 \pm 3.2(16)\end{array}$ & $\begin{array}{l}12.8 \pm 1.3(20)^{* * *} \\
36.2 \pm 2.5(20)\end{array}$ & $t(2)=4.43^{* c}$ \\
\hline \multicolumn{5}{|c|}{ Percentage conversion into phospholipid versus triglyceride (data from Zhao and Zera, 2002) } \\
\hline
\end{tabular}

a Mean \pm SEM DPM incorporated into $\left[\mathrm{CO}_{2} /\left(\mathrm{CO}_{2}+\right.\right.$ triglyceride + phospholipid $\left.)\right] \times 100$ within a $\mathrm{LW}(\mathrm{f})$ or SW stock; numbers in parentheses are sample sizes.

b Percentages differ between morphs within each block (*** $p<0.005)$ as determined by ANCOVA of DPM in CO 2 with DPM in $\left(\mathrm{CO}_{2}+\right.$ triglyceride + phospholipid $)$ as the covariate.

c Percentages differ between pairs of LW(f) and SW stocks $\left({ }^{*} p<0.05\right)$.

${ }^{\mathrm{d}}$ Mean \pm SEM DPM incorporated into [phospholipid/(triglyceride + phospholipid)] $\times 100$ within a LW(f) or SW stock; numbers in parentheses are sample sizes.

e Percentages differ between morphs within each block $\left({ }^{* *} p<0.025\right)$ as determined by ANCOVA of DPM in phospholipid with DPM in triglyceride plus phospholipid as the covariate.

rate of oxidation was highest on the "sucrose" diet. No consistent rank-order differences were observed between oxidative rates measured on the "high" or "low" diets across the three blocks, for either palmitate or acetate oxidation.

\subsection{Genetically based trade-off between fatty acid oxidation versus conversion into triglyceride and phospholipid.}

In each of the three blocks, a significantly greater percentage of radiolabeled $\left[{ }^{14} \mathrm{C}\right]$ palmitate was oxidized as opposed to being converted into triglyceride and phospholipid (= "total lipid") by SW versus LW(f) females (Table 1). Increased conversion of radiolabel into $\mathrm{CO}_{2}$ versus total lipid was of large magnitude, ranging from 32 to $180 \%$ in SW versus LW(f) females in the various blocks. More importantly, mean percentage ${ }^{14} \mathrm{C}$ from palmitate converted into $\mathrm{CO}_{2}$ versus triglyceride plus phospholipid was significantly greater in the three LW(f) stocks compared with the three SW stocks (paired $t$-test; Table 1). These results clearly demonstrate a strong, genetically based trade-off between oxidation of fatty acid versus conversion of fatty acid into triglyceride and phospholipid in morphs of G. firmus: LW(f) stocks preferentially convert fatty acid into triglyceride and phospholipid, while SW stocks preferentially oxidize fatty acid (Figure 4).

\subsection{Correlations}

On day 5 of adulthood, highly significant negative correlations were observed between the percentage of radiolabel derived from palmitic acid that was incorporated into $\mathrm{CO}_{2}$ versus triglyceride for each of the three blocks (see Table 2 for correlation coefficients and Figure 5 for scatterplots of data from a representative block). Similarly, the percentage radiolabel incorporated into triglyceride was also negatively correlated with percentage incorporated into phospholipid in each of the three blocks (Table 2; Figure 5). By contrast, the correlation between percent incorporation into $\mathrm{CO}_{2}$ versus phospholipid varied in sign across blocks and was not significant in two of three cases.

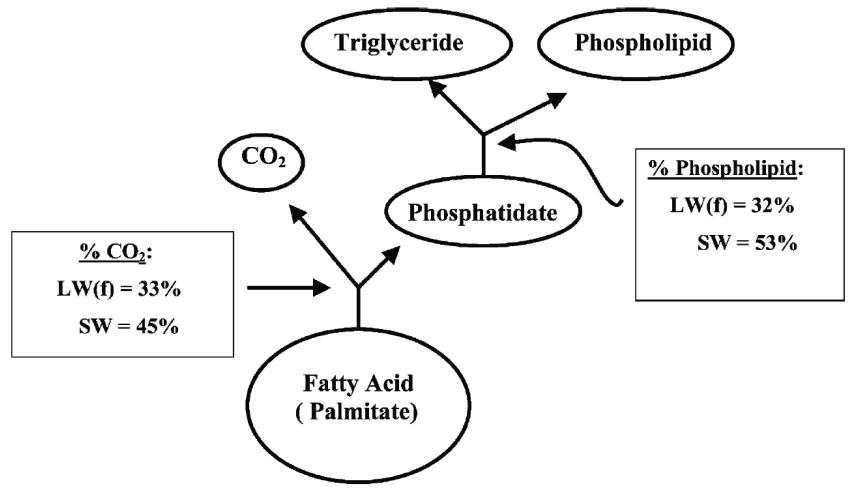

Figure 4. Nested biochemical trade-offs in flight-capable [LW(f)] and flightless (SW) morphs of G. firmus. Trade-offs are denoted as a difference in percentage incorporation of radiolabeled fatty acid into (1) $\mathrm{CO}_{2}$ versus (triglyceride + phospholipid) or (2) triglyceride versus phospholipid in LW(f) versus SW stocks. Percentages are medians of stock means from Table 1; percentages differed significantly between $\mathrm{LW}(\mathrm{f})$ and SW stocks in both cases (Table 1). $\% \mathrm{CO}_{2}=100 \times(\mathrm{DPM}$ in $\mathrm{CO}_{2} /\left(\mathrm{DPM}\right.$ in $\mathrm{CO}_{2}+$ triglyceride + phospholipid $\left.)\right) ; \%$ Phospholipid $=100 \times($ DPM in phospholipid $/$ (DPM in triglyceride + phospholipid)). 
Table 2. Phenotypic correlations between the percentage radiolabelled fatty acid converted into $\mathrm{CO}_{2}$, triglyceride, and phospholipid in LW(f) and SW morphs of G. firmus from three pairs of selected lines (3 blocks)

\begin{tabular}{|c|c|c|}
\hline \multirow[t]{2}{*}{ Variable 1} & \multicolumn{2}{|l|}{ Other variables } \\
\hline & TRIGLY & PHOS \\
\hline $\begin{array}{l}\mathrm{CO}_{2} \\
\text { TRIGLY }\end{array}$ & $\begin{array}{l}-0.90\left(^{* * *}\right),-0.88(* *),-0.79\left(^{* *}\right)^{\mathrm{a}} \\
-\end{array}$ & 0.256 (n.s.), $-0.67\left({ }^{* *}\right), 0.041$ (n.s.) \\
\hline PHOS & $-0.60\left(^{* *}\right),-0.48\left(^{*}\right),-0.59\left(^{* *}\right)$ & - \\
\hline
\end{tabular}

a Values are phenotypic correlations (significance levels) from LW-selected and SW-selected lines from blocks 1, 2, or 3, respectively. Sample sizes ranges from 41 to 44 individuals per block. Significance levels were based on tests involving two independent variables $\left({ }^{* * *} p<0.005 ;{ }^{* *} p<0.01 ;{ }^{*} p<0.05\right.$, n. s. = non-significant). Data were pooled across the three diets; TRIGLY = triglyceride; PHOS $=$ phospholipid (lipid data are from Zhao and Zera, 2002).
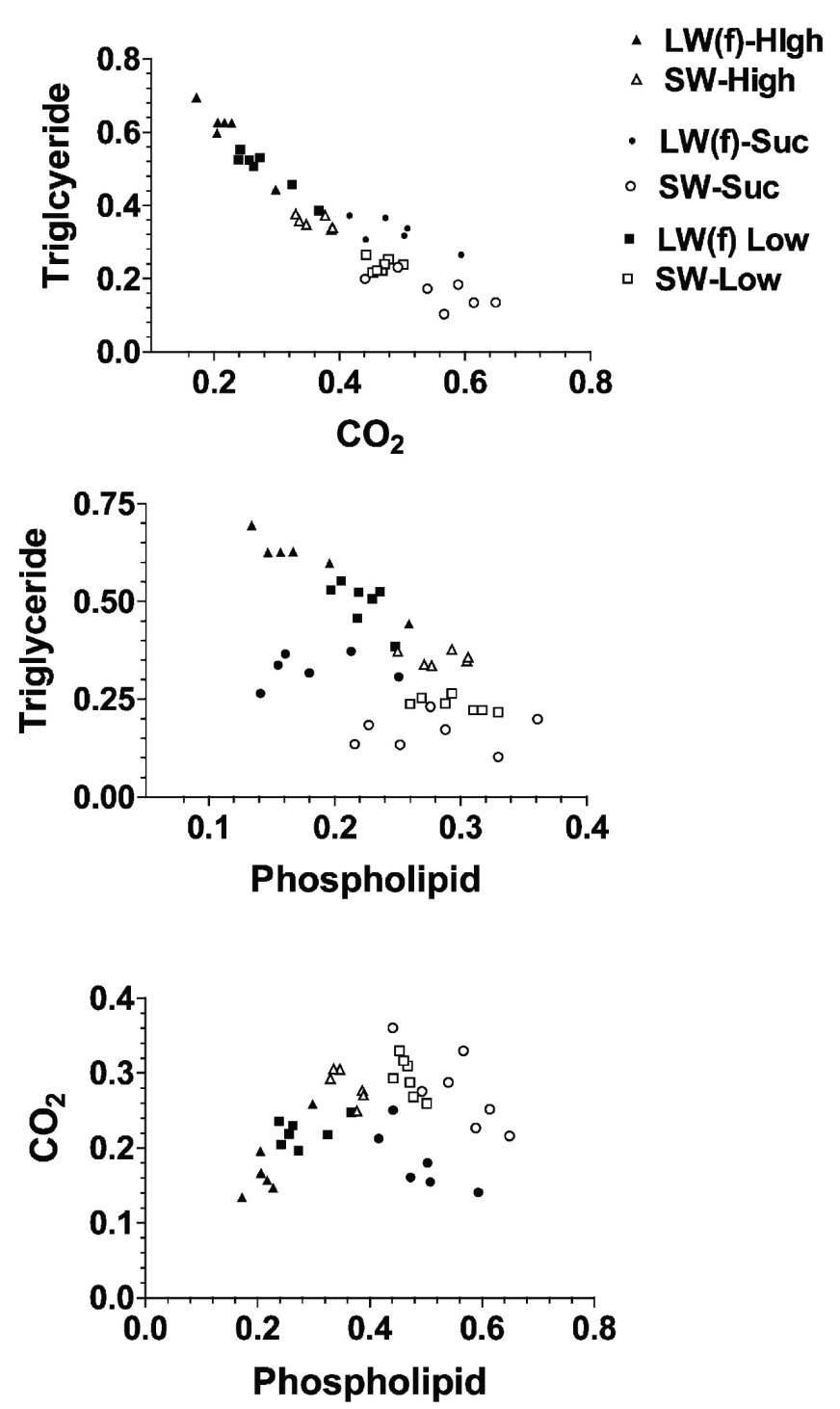

Figure 5. Phenotypic correlations between proportion of radiolabeled palmitate incorporated into $\mathrm{CO}_{2}$, triglyceride or phospholipid in flight-capable [LW(f); closed symbols] and flightless (SW; open symbols) Gryllus firmus from a representative block (block 1) fed various diets. Correlation coefficients are in Table 2. See "Materials and Methods" for information on diets.

\section{Discussion}

\subsection{Overview}

Two important results were obtained in the present study. First, we documented a large-magnitude, genetically based elevation in lipid oxidation in the SW morph relative to the $L W(\mathrm{f})$ morph of G. firmus measured in vivo. Morph-specific differences in rate of lipid oxidation occurred on all diets and appeared to be functionally important with respect to the trade-off between triglyceride accumulation and ovarian growth. Second, we documented a genetically based trade-off between the oxidation of fatty acid versus utilization for biosynthesis of triglyceride and phospholipid in G. firmus. Each of these results has important implications for the biochemical mechanisms underlying morph specialization for flight versus reproduction in G. firmus, and for the mechanistic basis of life history evolution.

\subsection{Functional significance of differences in lipid oxidation between morphs}

Zera and Larsen (2001) previously documented that the LW(f) morph of G. firmus has higher whole-body triglyceride and total lipid contents than the SW morph. The elevated content of triglyceride, which is the main flight fuel in species of Gryllus (Zera et al., 1999), was of large magnitude [ca $40 \%$ higher in the LW(f) morph], is genetically based, and was produced during the first week of adulthood (Figure 6). The elevated triglyceride and total lipid contents also were strongly associated with substantially reduced (50-75\%) ovarian growth in the LW(f) morph (Figure 6), and were not due to enhanced lipid assimilation from the diet (Zera and Brink, 2000; Zera and Larsen, 2001). These data were collectively viewed as strongly supporting the hypothesis that there is a direct trade-off between internal nutrients allocated to ovarian growth versus flight fuel (triglyceride) production in morphs of G. firmus during the first week of adulthood (Zhao and Zera, 2001; Zera and Harshman, 2001). Substantially higher in vitro activities of lipogenic enzymes, in vivo rate of triglyceride biosynthesis, and allocation of biosynthesized triglyceride to somatic tis- 

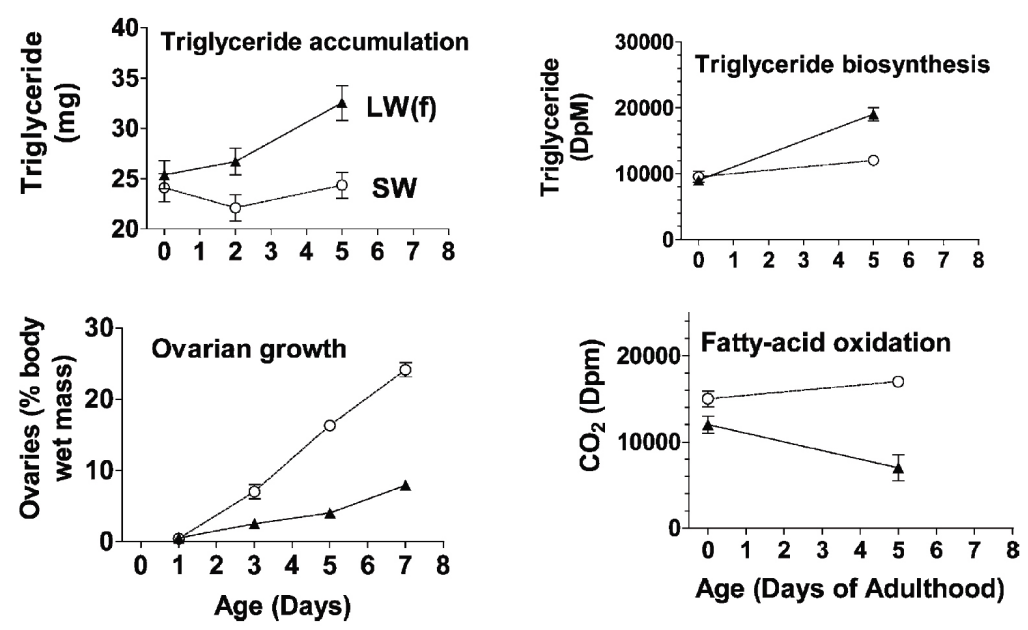

Figure 6. Relationships among triglyceride accumulation, ovarian growth, triglyceride biosynthesis, and fatty acid oxidation in flight capable [LW(f), filled symbols] and flightless (SW, open symbols) G. firmus during the first week of adulthood. Note the positive associations between triglyceride accumulation and biosynthesis, and between fatty acid oxidation and ovarian growth. Data for triglyceride accumulation and ovarian growth are taken from Zera and Larsen (2001), while data for triglyceride biosynthesis are taken from Zhao and Zera (2002). The rates of fatty acid oxidation are data for palmitate oxidation pooled across blocks (Figure 2).

sue in $L W(f)$ versus SW females on day five of adulthood (Zhao and Zera, 2002; Zera and Zhao, 2003), provided additional support for this hypothesis.

The results of the present study suggest that morphspecific differences in fatty acid oxidation also play an important role in the genetically based trade-off between flight fuel production and ovarian growth in G. firmus. During the first 5 days of adulthood, fatty acid oxidation changed from being equivalent (acetate) or nearly equivalent (palmitate) in the morphs, to being substantially and significantly lower in LW(f) versus SW females on nearly all blocks and diets, irrespective of whether radiolabelled palmitate or acetate was the substrate (Figure 2 and Figure 3). The large magnitude reduction in fatty acid oxidation in LW(f) females, compared with SW females, was observed precisely when elevated triglyceride accumulation was first seen in the LW(f) morph (Figure 6). These data collectively suggest that both a diversion of nutrients away from fatty acid oxidation for energy production, and increased allocation of fatty acids to triglyceride biosynthesis contribute significantly to the greater accumulation of triglyceride reserves in $\mathrm{LW}(\mathrm{f}) \mathrm{G}$. firmus during the first week of adulthood. This hypothesis is strengthened by the results of a hormone manipulation experiment, in which an experimentally induced increase in fatty acid oxidation was associated with decreased accumulation of triglyceride, and increased ovarian growth (discussed below).

In an analogous manner, increased fatty acid oxidation occurred precisely when enhanced ovarian growth was first seen in the SW morph, which in turn was correlated with a reduction in the biosynthesis of triglyceride (Table 2; Figure 4 and Figure 5). These data col- lectively suggest that enhanced ovarian growth requires a diversion of nutrients away from triglyceride biosynthesis, and that the oxidation of fatty acids provides energy to fuel ovarian growth. This hypothesis is strengthened by the correlated increase in fatty acid oxidation and ovarian growth in the hormone manipulation experiment discussed above (see below).

MORPH $\times$ DIET interactions were not observed for most cases of palmitate or acetate oxidation (Results), similar to the situation for the biosynthesis of triglyceride from either of these two precursors (Zhao and Zera, 2002). Thus, elevated catabolism and reduced biosynthesis of lipid in SW versus LW(f) G. firmus, appear to be "robust" differences between the SW and LW(f) morphs, that are observed under a wide range of environmental conditions. The existence of these "robust" differences of large magnitude make wing polymorphism a powerful experimental model for investigating the biochemical underpinnings of trade-offs between dispersal and reproduction. By contrast, expression of many physiological correlates of life history traits in other model organisms (e.g. Drosophila) are often exceedingly sensitive to environmental conditions (Rose et al., 1996; Harshman and Hoffmann, 2000; Zera and Harshman, 2001).

The results of the present, and previous studies (Zhao and Zera, 2001; Zhao and Zera, 2002; Zera and Zhao, 2003), indicate that a remarkable, global reorganization of lipid metabolism has accompanied the evolution of a flightlessness phenotype with enhanced reproductive output in G. firmus (Figure 4 and Figure 6). Not only have radiotracer studies documented large-magnitude, genetically based differences between the morphs in flux through pathways of both lipid biosynthesis and oxidation (Zhao and Zera, 2001; Zhao and Zera, 2002; 
Figure 4 and Figure 6), analogous differences have also been found between morphs in flux through pathways of amino-acid catabolism (e.g. amino-acid oxidation and conversion to lipid; A. J. Zera and Z. Zhao, unpublished data). Furthermore, morphs differ significantly in the activity of every enzyme involved in lipid biosynthesis, fatty acid oxidation, or amino acid catabolism, that we have studied, in either fat bodies or flight muscles (Zera et al., 1999; Zhao and Zera, 2001; Zera and Zhao, 2003).

The extent to which analogous, large-magnitude differences in multiple pathways of intermediary metabolism occur between dispersing and reproductive morphs of other species, or between laboratory stocks of insects differing in life history traits, is currently unknown. In a number of dispersal-polymorphic species, substantial morph-specific differences in lipid reserves have been reported that are similar to those found between morphs of G. firmus (e.g. Uvarov, 1966; Newanze et al., 1976; Gunn and Gatehouse, 1987). Similarly, large-magnitude differences in lipid levels have been reported between genetic stocks of $D$. melanogaster that differ in life history traits, such as longevity, early age reproduction, and stress resistance (Service, 1987; Chippindale et al., 1996; Djawdan et al., 1996; Zera and Harshman, 2001). However, the biochemical processes responsible for these morph, phase, or stock specific differences remain largely unknown (Zera et al., 1999; Zera and Harshman, 2001). In vitro activities of only a few lipid-metabolizing enzymes have been compared between stocks of $D$. melanogaster, and in no case, other than for G. firmus, have in vivo studies of lipid catabolism or biosynthesis been undertaken that involve genetic stocks differing in life history traits (reviewed in Zera and Harshman, 2001; Zhao and Zera, 2002; Zera and Zhao, 2003; see below).

A wide variety of biochemical, physiological, morphological, and reproductive traits covary in G. firmus, giving rise to morphs that are specialized for reproduction or flight capability (Zera and Denno, 1997; Zera and Harshman, 2001; Figure 6). Clearly, genetically variable regulators must exist within $\mathrm{G}$. firmus which co-ordinate and integrate the expression of these various traits. An important question in dispersal polymorphism in particular, and life history evolution in general, is the nature of the genetically variable regulators which underlie life history trade-offs (Zera and Harshman, 2001; Leroi, 2001). One likely candidate regulator in G. firmus is juvenile hormone. Previous studies have shown that application of the JH analogue methoprene to LW(f) females, increases the mass of the ovaries, decreases total lipid and triglyceride accumulation, and decreases rates of triglyceride biosynthesis (Zera and Cisper, 2001; Zera and Cisper, 2001; Zhao and Zera, 2002). More recent hormone-manipulation experiments have shown that methoprene also causes an increase in fatty acid oxidation from either palmitate or acetate (Zera and Zhao, unpublished data). That is, methoprene produces a SW phe- nocopy, causing $L W(f)$ females to express reproductive, morphological, and biochemical traits seen in unmanipulated SW females. These data suggest that morph-specific differences in the $\mathrm{JH}$ titer or tissue sensitivity to $\mathrm{JH}$ may play a role in coordinating the expression of the large number of morphological, physiological, and biochemical traits that define LW(f) and SW morphs in G. firmus (see Discussion in Zera and Zhao, 2003). As discussed previously, the results of the hormone manipulation experiment also provide independent support for the hypothesis that increased oxidation of fatty acids is causally related to increased ovarian growth and decreased triglyceride accumulation.

\subsection{Genetically based, biochemical trade-offs in Gryllus firmus.}

Trade-offs (negative associations) commonly exist between life history traits such as early age fecundity and longevity or dispersal capability (Stearns, 1992; Zera and Harshman, 2001; Roff, 2002). However, the functional causes of these trade-offs remain largely unknown, and constitute one of the most important unsolved problems in life history physiology-biochemistry (Zera and Harshman, 2001). In a number of cases, trade-offs between physiological traits, such as somatic energy reserves and ovarian mass, have been identified that are important components of the higher level demographic trade-offs mentioned already (reviewed in Zera and Harshman, 2001). These physiological trade-offs are presumed to arise from the differential allocation of limited internal resources, which necessitate that increased allocation to one trait (e.g. ovarian growth) be accompanied by decreased allocation to the other (e.g. somatic reserves). However, few studies have directly documented the differential flux of metabolites through pathways of intermediary metabolism which give rise to physiological trade-offs ([O'Brien et al., 2002; Zera and Zhao, 2003). In the present and previous studies (Table 1; Figure 5; Zhao and Zera, 2002), we used radioisotopic methods and ANCOVA to directly quantify the differential flow of radiolabelled carbon from palmitic acid into $\mathrm{CO}_{2}$, triglyceride, and phospholipid. This approach is analogous to the method of Zamer and Hoffmann (1989) who demonstrated the differential partitioning of carbon between glycolysis and the pentose shunt by phosphoglucose isomerase genotypes in a sea anemone. To our knowledge, the present study and that of Zhao and Zera (2002) represent the first definitive demonstrations of genetically based, biochemical trade-offs that underlie a life history trade-off. Thus far two nested trade-offs have been identified in G.firmus:

1. differential partitioning of fatty acid into oxidative pathways for energy production versus production of triglyceride and phopholipid; and 
2. a subsequent downstream trade-off between the production of phospholipid and triglyceride (Figure 4).

Correlational analyses (Table 2, Figure 5) confirm the identification of these trade-offs identified by ANCOVA (Table 1 and Figure 4).

4.4. Future prospects: Integrating evolutionary studies of dispersal polymorphism, life history evolution, and metabolic biochemistry

Variation in life history traits, such as dispersal capability and reproductive output, must be strongly influenced by variation in aspects of metabolism involved in the production of components of these traits, such as yolk protein for eggs and triglyceride for dispersal. Thus, a deep understanding of the mechanisms underlying the evolution of flightlessness and enhanced reproductive output requires detailed knowledge of the aspects of intermediary metabolism that have been altered to produce phenotypic variation and covariation in these life history components.

Thus far, the synthesis between life history evolution and metabolic biochemistry is at a rudimentary stage. For example, despite the considerable number of inter and intra-specific studies of biochemical adaptation of metabolic pathways and enzymes (Hochachka and Somero, 1984; Prosser, 1986; Zera et al., 1985; Watt and Dean, 2000; Powers, 1987; Clark, 1989; Clark, 1990), only a handful of investigations have explicitly focused on variation in in vitro activities of enzymes of central metabolism in the context of life history microevolution (Harshman and Schmid, 1998; Harshman et al., 1999; Zhao and Zera, 2001; Zera and Zhao, 2003; reviewed in Zera and Harshman, 2001). Even fewer studies have quantified in vivo differences in flux through metabolic pathways in organisms that differ in life history traits (Boggs, 1997; O'Brien et al., 2002; Zhao and Zera, 2002), and only two studies have reported on genetically based differences in in vivo metabolism between phenotypes that also differ in life histories (present study; Zhao and Zera, 2002). Finally, evolutionary modification of the regulatory controls of intermediary metabolism in the context of life history evolution remains virtually unstudied. The present study, in which large-magnitude differences in the biochemical-genetic correlates of life history variation and trade-offs were documented, attests to the utility of wing polymorphism as a model for integrating studies of life history evolution with metabolic biochemistry.

\section{Acknowledgments}

The work was supported by the National Science Foundation (IBN 9808249).

\section{References}

Beenakkers et al., 1985. A. T. M. Beenakkers, D. J. Van Der Horst and W. J. A. Van Merrewijk, Biochemical processes directed to flight muscle metabolism. In: G. A. Kerkut and L. I. Gilbert, Editors, Comprehensive Insect Physiology, Biochemistry, and Pharmacology vol. 10, Pergamon, Oxford (1985), pp. 451-486.

Boggs, 1997. C. Boggs, Dynamics of reproductive allocation from juvenile and adult feeding: radiotracer studies. Ecology 74 (1997), pp. 433-441.

Candy, 1989. D. J. Candy, Utilization of fuels by the flight muscles. In: G. J. Goldworthy and C. H. Wheeler, Editors, Insect Flight, CRC Press, Boca Raton, FL (1989), pp. 305-319.

Clark, 1989. A. G. Clark, Causes and consequences of variation in energy storage in Drosophila melanogaster. Genetics 123 (1989), pp. 131-144.

Clark, 1990. A. G. Clark, Genetic components of variation in energy storage in Drosophila melanogaster. Evolution 44 (1990), pp. 637-650.

Chippindale et al., 1996. A. K. Chippindale, T. J. Chu and M. R. Rose, Complex trade-offs and the evolution of starvation resistance in Drosophila melanogaster. Evolution 50 (1996), pp. 753-766.

Dingle, 1996. H. Dingle. Migration: the Biology of Life on the Move, Oxford University Press, Oxford (1996).

Djawdan et al., 1996. M. Djawdan, T. T. Sugiyama, L. K. Schlaeger, T. J. Bradley and M. R. Rose, Metabolic aspects of the trade-off between fecundity and longevity in Drosophila melanogaster. Physiological Zoology 69 (1996), pp. 1176-1195.

Downer, 1985. R. G. H. Downer, Lipid Metabolism. In: G. A. Kerkut and L. I. Gilbert, Editors, Comprehensive Insect Physiology, Biochemistry, and Pharmacology vol. 10, Pergamon, Oxford (1985), pp. 77-114.

Geer and Laurie-Ahlberg, 1984. B. W. Geer and C. C. LaurieAhlberg, Genetic variation in the dietary sucrose modulation of enzyme activities in Drosophila melanogaster. Genetic Research Cambridge 43 (1984), pp. 307-321.

Gunn and Gatehouse, 1987. A. Gunn and A. G. Gatehouse, The influence of larval phase on metabolic reserves, fecundity, and lifespan of the African armyworm moth, Spodoptera exempta (Walker) (Lepidoptera: Noctuidae). Bulletin of Entomological Research 77 (1987), pp. 6451-6660.

Harshman and Hoffmann, 2000. L. G. Harshman and A. A. Hoffmann, Laboratory selection experiments using Drosophila: what do they really tell us. Trends in Ecology and Evolution 15 (2000), pp. 32-36.

Harshman and Schmid, 1998. L. G. Harshman and J. L. Schmid, Evolution of starvation resistance in Drosophila melanogaster: aspects of metabolism and counter-impact selection. Evolution 52 (1998), pp. 1679-1685.

Harshman et al., 1999. L. G. Harshman, A. A. Hoffmann and A. G. Clark, Selection for starvation resistance in Drosophila melanogaster: physiological correlates, enzyme activities and multiple stress responses. Journal of Evolutionary Biology 12 (1999), pp. 370-379. 
Hochachka and Somero, 1984. P. W. Hochachka and G. N. Somero. Biochemical Adaptation, Princeton University Press, Princeton (1984).

Leroi, 2001. A. M. Leroi, Molecular signals versus the Loi de Balancement. Trends in Ecology and Evolution 16 (2001), pp. 24-29.

Newanze et al., 1976. K. F. Newanze, J. K. Maskarinec and T. L. Hopkins, Lipid composition of normal and flight forms of adult cowpea weevils, Callosobruchus maculatus. Journal of Insect Physiology 22 (1976), pp. 897-899.

O'Brien et al., 2002. D. M. O'Brien, M. L. Marilyn and C. Boggs, Renewable and nonrenewable resources: Amino acid turnover and allocation to reproduction. Proceedings of the $\mathrm{Na}$ tional Academy of Sciences USA 99 (2002), pp. 4413-4418.

Prosser, 1986. C. L. Prosser. Adaptational Biology. Molecules to Organisms, Wiley (1986).

Powers, 1987. D. A. Powers, A multidisciplinary approach to the study of genetic variation within species. In: M. E. Feder, A. F. Bennett, W. W. Burggren and R. B. Huey, Editors, New Directions in Ecological Physiology, Cambridge University Press, Cambridge (1987), pp. 102-134.

Roff, 2002. D. A. Roff. Life History Evolution, Sinauer (2002).

Rose et al., 1996. M. R. Rose, T. J. Nusbaum and A. K. Chippindale, Laboratory evolution: the experimental wonderland and the Cheshire cat syndrome. In: M. R. Rose and G. V. Lauder, Editors, Adaptation, Academic Press, San Diego (1996), pp. 221-241.

Service, 1987. P. M. Service, Physiological mechanisms of increased stress resistance in Drosophila melanogaster selected for postponed senescence. Physiological Zoology 60 (1987), pp. 321-326.

Stearns, 1992. S. C. Stearns. The Evolution of Life Histories, Oxford University Press, Oxford (1992).

Uvarov, 1966. B. Uvarov. Grasshoppes and Locusts vol. 1, Cambridge University Press, London (1966).

Veazy et al., 1976. J. N. Veazy, C. A. R. Kay, T. J. Walker and W. H. Whitcomb, Seasonal abundance, sex ratio, and macroptery of field crickets in northern Florida. Annals of the Entomological Society of America 69 (1976), pp. 374-380.

Watt and Dean, 2000. W. B. Watt and A. M. Dean, Molecularfunctional studies of adaptive genetic variation in prokaryotes and eukaryotes. Annual Review of Ecology and Systematics 34 (2000), pp. 593-622.

Zamer and Hoffmann, 1989. W. E. Zamer and R. J. Hoffmann, Allozymes of glucose-6-phosphate isomerase differentially modulate pentose-shunt metabolism in the sea anemone Metridium senile. Proceedings of the National Academy of Sciences USA 86 (1989), pp. 2737-2741.

Zera and Bottsford, 2001. A. J. Zera and J. Bottsford, The endocrine-genetic basis of life-history variation: Relationship between the ecdysteroid titer and morph-specific reproduction in the wing-polymorphic cricket, Gryllus firmus. Evolution 55 (2001), pp. 538-549.

Zera and Brink, 2000. A. J. Zera and T. Brink, Nutrient absorption and utilization by wing and flight muscle morphs of the cricket Gryllus firmus: implications for the trade-off be- tween flight capability and early reproduction. Journal of Insect Physiology 46 (2000), pp. 1207-1218.

Zera and Cisper, 2001. A. J. Zera and G. C. Cisper, Genetic and diurnal variation in the juvenile hormone titer in a wingpolymorphic cricket: Implications for the evolution of life histories and dispersal. Physiological and Biochemical Zoology 74 (2001), pp. 293-306.

Zera and Denno, 1997. A. J. Zera and R. F. Denno, Physiology and ecology of dispersal polymorphism in insects. Annual Review of Entomology 42 (1997), pp. 207-231.

Zera and Harshman, 2001. A. J. Zera and L. G. Harshman, The physiology of life history trade-offs in animals. Annual Review of Ecology and Systematics 32 (2001), pp. 95-126.

Zera and Larsen, 2001. A. J. Zera and A. Larsen, The metabolic basis of life history variation: genetic and phenotypic differences in lipid reserves among life history morphs of the wing-polymorphic cricket, Gryllus firmus. Journal of Insect Physiology 47 (2001), pp. 1147-1160.

Zera and Zhao, 2003. A. J. Zera and Z. Zhao, Life-history evolution and the micoevolution of intermediary metabolism: activities of lipid-metabolizing enzymes in life-history morphs of a wing-dimorphic cricket. Evolution 57 (2003), pp. 586-596.

Zera et al., 1985. A. J. Zera, R. K. Koehn and J. G. Hall, Allozymes and biochemical adaptation. In: G. A. Kerkut and L. I. Gilbert, Editors, Comprehensive Insect Physiology, Biochemistry, and Pharmacology vol. 10, Pergamon, Oxford (1985), pp. 633-674.

Zera et al., 1994. A. J. Zera, S. Mole and K. Rokke, Lipid, carbohydrate and nitrogen content of long- and short-winged Gryllus firmus: implications for the physiological cost of flight capability. Journal of Insect Physiology 40 (1994), pp. 1037-1044.

Zera et al., 1998. A. J. Zera, J. Potts and K. Kobus, The physiology of life history trade-offs: experimental analysis of a hormonally-induced life history trade-off in Gryllus assimilis. American Naturalist 152 (1998), pp. 7-23.

Zera et al., 1997. A. J. Zera, J. Sall and K. Grudzinski, Flightmuscle polymorphism in the cricket Gryllus firmus: muscle characteristics and their influence on the evolution of flightlessness. Physiological Zoology 70 (1997), pp. 519-529.

Zera et al., 1999. A. J. Zera, J. Sall and K. Otto, Biochemical aspects of flight and flightlessness in Gryllus: flight fuels, enzyme activities, and electrophoretic profiles of flight muscles from flight-capable and flightless morphs. Journal of Insect Physiology 45 (1999), pp. 275-285.

Zhao and Zera, 2001. Z. Zhao and A. J. Zera, Enzymological and radiotracer studies of lipid metabolism in the flightcapable and flightless morphs of the wing-polymorphic cricket, Gryllus firmus. Journal of Insect Physiology 47 (2001), pp. 1337-1347.

Zhao and Zera, 2002. Z. Zhao and A. J. Zera, Differential lipid biosynthesis underlies a trade-off between reproduction and flight capability in a wing-polymorphic cricket. Proceedings of the National Academy of Sciences USA 99 (2002), pp. 16829-16834. 